\title{
A Study of Center of Gravity in Different Phases of Selected Soccer Kicks
}

\author{
Shaybal Chanda ${ }^{*}$, Sumanta Kumar Mondal \\ Department of Physical Education and Sport Science, Visva-Bharati University, Santiniketan, India \\ Email address: \\ shaybalchanda@yahoo.com (S. Chanda),sumantavb@gmail.com (S. K. Mondal) \\ ${ }^{*}$ Corresponding author
}

\section{To cite this article:}

Shaybal Chanda, Sumanta Kumar Mondal. A Study of Center of Gravity in Different Phases of Selected Soccer Kicks. American Journal of Life Sciences. Vol. 7, No. 4, 2019, pp. 75-82. doi: 10.11648/j.ajls.20190704.12

Received: September 15, 2019; Accepted: September 29, 2019; Published: October 15, 2019

\begin{abstract}
The center of gravity (CG) of the human body is a hypothetical point around which the force of gravity appears to act. CG need not lie within the physical bounds of an object. Human beings do not remain fixed in the anatomical position and the precise location of the CG changes constantly with every new position of the body and limbs. CG plays an important role in maintaining balance, equilibrium, and breaking inertia during the performance of a sports technique. Purpose of this study is to discover the pattern and make the comparison of CG height and CG velocity changes in the execution of frequently used soccer kicks within and between the kicks by the male players. Five male players played for the Bangladesh National Football teams were selected as subject and their age was between 16-19 years. A Cannon EOS7D with the capacity of 55 f/sec camera placed on sagittal plane at the backside of the kick 5.00 meters away and at 1.13 meter of height to capture kicking actions of the players on Coronal/Frontal plane. The best frame was selected out of 3 trials. 2D motion Analysis Software Kinovea 0.8 .25 was employed for the quantitative analysis of the video clips. Changing of the CG height position in percentage was studied in three different phases i.e. Ground contact, Ball contact, and Follow-through in reference to erect standing CG height of the players. In addition, CG velocity changes were also studied in ball contact and follow-through phases. This study demonstrates that the male soccer players demonstrate inconsistency in CG height reduction in performing all three phases (Ground Contact, Ball Contact, \& Follow-through) in all selected five kicks (Push Pass, Instep Kick, Lofted Kick, Chip Shot, and In-swerve Kick), but highest reductions have been located in the ball contact phase of all the kicks. Players change CG height in the same manner among the five selected kicks in each of the phases distinctly. Players experience CG height drop in Instep Kick differently between ball contact and ground contact phases. Players display higher mean CG velocity in ball contact phase than follow-through phase in Push Pass but remaining other kicks exhibit opposite actions. Players display CG velocity in all selected soccer kicks in the same manner at ball contact and follow-through phases. Players change CG velocity differently between Push Pass and Instep Kick, In-swerve Kick, Lofted Kick at follow-through phase.
\end{abstract}

Keywords: Center of Gravity Height, Soccer Kick, Center of Gravity Velocity

\section{Introduction}

McGinnis [1], "The center of gravity is the point at which the entire mass or weight of the body may be considered to be concentrated." Center of Gravity (CG) is "the point through which the resultant of the gravitational forces on a body always acts" [2]. Rai [3] defined that "Centre of gravity is an imaginary point in a body at which the sum of partial gravity forces of all the body parts acts." He noted further that the human body is not like geometrically symmetrical, thus CG shifts towards the heavier side, and it does not remain constant due to the multi-segmented structure and relative movements of the segments. Furthermore, CG may shift outside of the physical limit according to body flexibility and complexity in action.

Assessing CG of human at erect standing position in twodimensional (2D) situation is difficult one, it lays front to back and side to side passes horizontally through the body 1 to 2 inches below the navel, and it is about $55 \%$ to $57 \%$ of the height of individual from the anatomical standing position [1].

Stability is the property of an individual or object to return 
to its previous position or equilibrium after being displaced. For a successful skill execution in sports, athletes either needs to maintain or quick break of stability. Stability depends on three factors i.e. height of $\mathrm{CG}$, size of base of support, and mass of the object or athlete. Hobbs [4] suggested, "Stability has been defined as the level of challenge at which one can still balance." Further opined, stability can be increased by lowering the CG. Soccer kick is a dynamic action and requires stability across the execution of the phases following principles of CG maintenance. In the postural balance analysis CG work as a parameter of clear indicator of postural balance [5].

To play many sports effectively CG plays a key role in anything that is associated with balance, in every sport including running to copper diving [6]. Goalkeepers in the Soccer sink their contra-lateral side's leg to prepare the platform for raising the CG just before diving for the ball [7]. The sinking of the leg allows lowering CG down that assist to have higher thrust to project the body farther and faster. During the execution of non-rotational kick in Soccer, players naturally pass the force vector acting from the kicking foot through the ball's center of gravity [8]. This application of force through CG results in higher velocity. To have a greater effect in Instep Kick, kicking with the foot's center of gravity is of immense importance [9]. Cetin \& Muratli [10], according to the positional play in basketball CG of players' height differ and contribute to the high performance. Spathopoulos [11] suggested that CG location is reliant on the shape of the athlete, so if the athlete changes the shape of the body CG position also changes accordingly even it may set entirely outside of the athlete's body as in the case of high jumper happen during the clearance of the crossbar. During the swing of the bat in baseball linear and angular acceleration is affected by the CG [12].

Martens, Deflandre, Shwartz, Dardenne, \& Bury [13], the center of gravity including 3 other variables: swing duration, stride frequency, step length be evidence for satisfactory stability in stride biomechanics of running during the fatigueinduced changes. Tanaka, Takeda, Izumi, Ino, \& Ifukube [14] expressed that the center of gravity in elderly adults is associated with following important factors such as the maximal displacement of the head, lumbar positions, and the toe's muscle activity. A bad posture alters the center of gravity of the player's body and results in chronic skeletal and muscle soreness [15]. More displacement of the center of gravity was identified in the knee of the operated side of the case group in compared to the non-operated knee side of the same subject for the all parameters of the force plate [16]. The knee of the operated side of the case group showed more displacement of the center of gravity when compared to the non-operated side in the same subject for all variables of the force plate.

The present study compares differences in CG height percentage changed and vertical CG velocity changed during execution of five popular kicks: Push Pass, Instep Kick, Lofted Kick, Chip Shot, and In-swerve Kick by the male players in Soccer.

\section{Methods}

\subsection{Selection of Subject}

Five male players were selected from Bangladesh Institute of Sports widely known as BKSP (Bangladesh Krira Shikha Protisthan), Dhaka, Bangladesh who have represented the Bangladesh National Soccer teams of different age groups. Their age was between 16-19 years. They were without any injury within the 6 months prior to the filming days.

\subsection{Selection of the Soccer Kicks}

Scholars selected five common soccer kicks: Push Pass, Instep Kick, Lofted Kick, Chip Shot, and In-swerve Kick in the present study.

\subsection{Delimitation of the Study}

CG height was studied at standing, P1, P2, and P3. CG velocity was studied at $\mathrm{P} 2$ and $\mathrm{P} 3$.

\subsection{Equipment and Technology}

Canon EOS7D camera, Kinovea 0.8.25 version pro-trainer standard motion analysis software, steel tape, well-inflated football.

\subsection{Set-up of Filming Protocol}

One camera was placed on the sagittal plane 5 meters away from the ball kicking spot and at the height of 1.13 meters. The camera started to role a few seconds before the kicking action start and stopped after completion of the Kicking actions. 12 (twelve) grids of 1-meter square each were marked keeping ball kicking spot at the center of grids to use as a reference scale. The camera was kept fix at one place throughout the period of video recording.

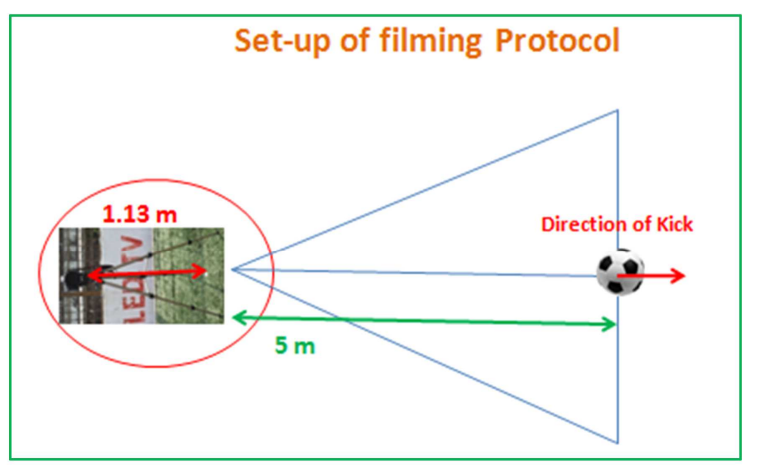

Figure 1. Set-up of Filming Protocol.

\subsection{Data Collection Procedure}

Scholar made clear regarding the purpose of the recording to the players. Demonstrations were made in front of players. Players performed with their strong leg on astroturf surface. Between the trials one minute and between the different types 
of kicks two minutes rest pauses were allowed, and fifteen minutes was given prior to kick for individual warm-up. Three trials of each type of kicks were allowed and the best trial out of expert observation was finally selected from each type of selected soccer kicks. Height was measured in centimeter. Vertical CG height was measure in four phases: Erect standing, P1- first ground contact of the weight-bearing foot at the last step to kick, P2- ball contact with the kicking foot, P3- maximum follow-through of kicking foot.

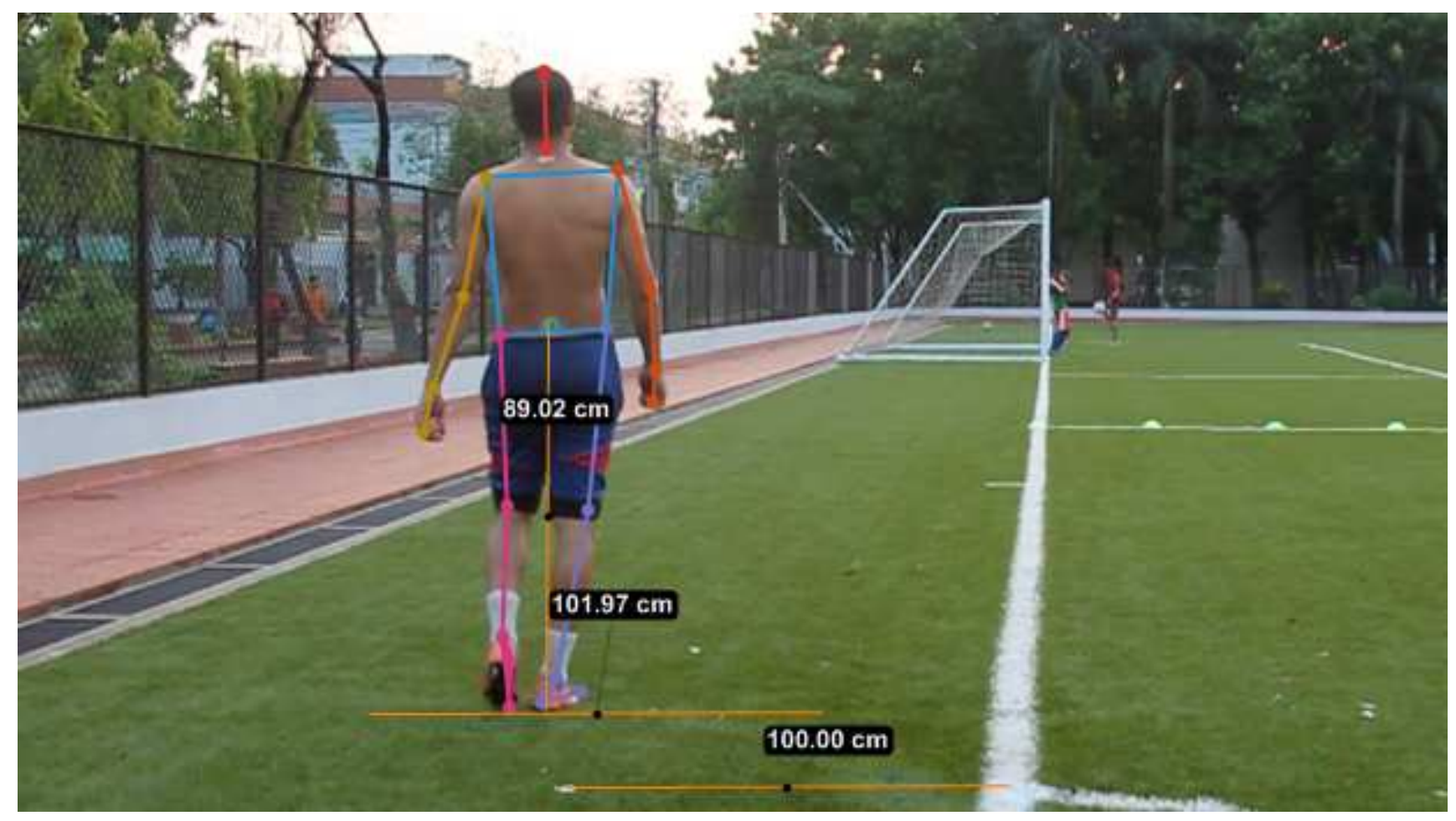

Figure 2. CG Standing.

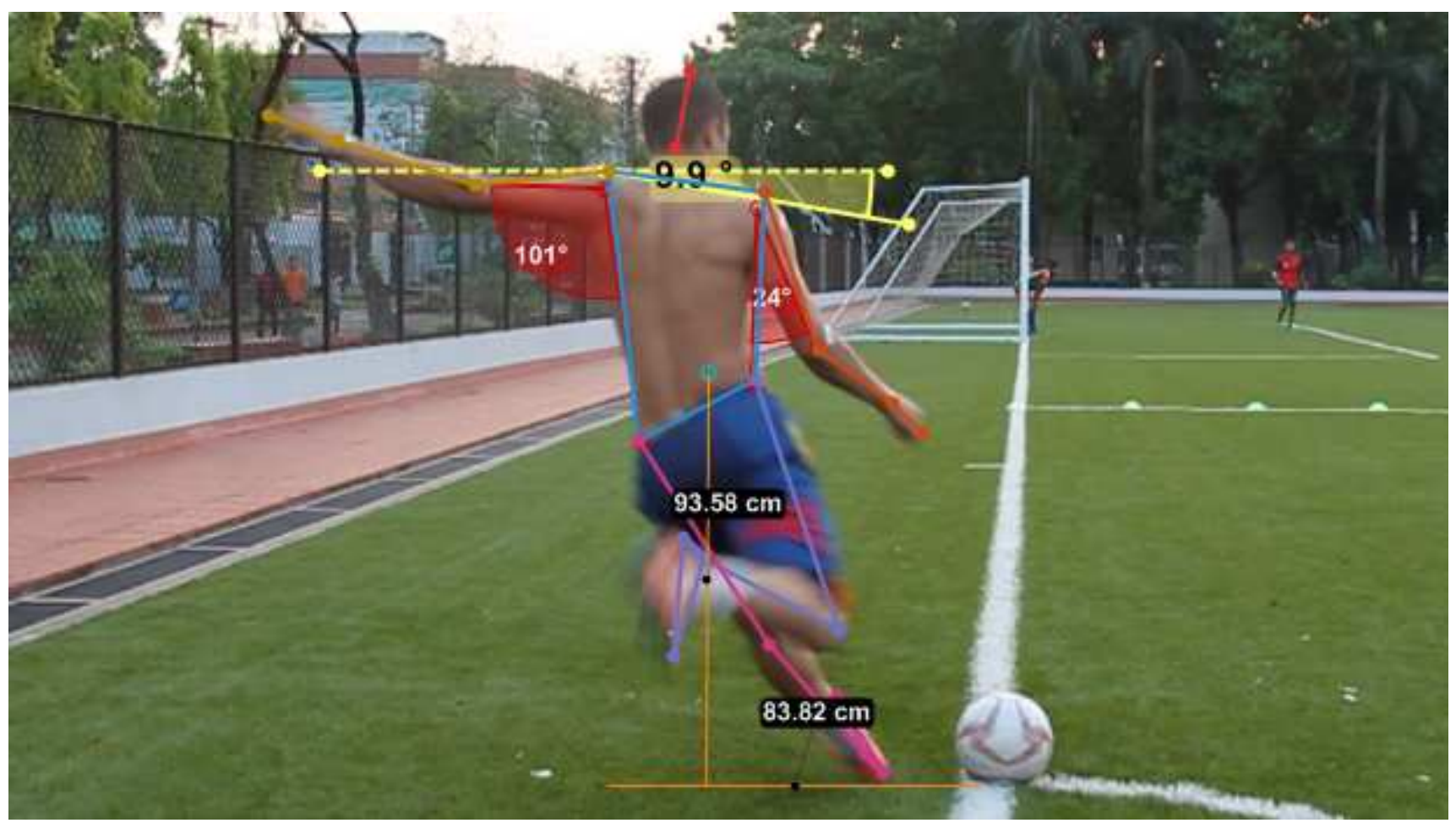

Figure 3. $C G P 1$. 


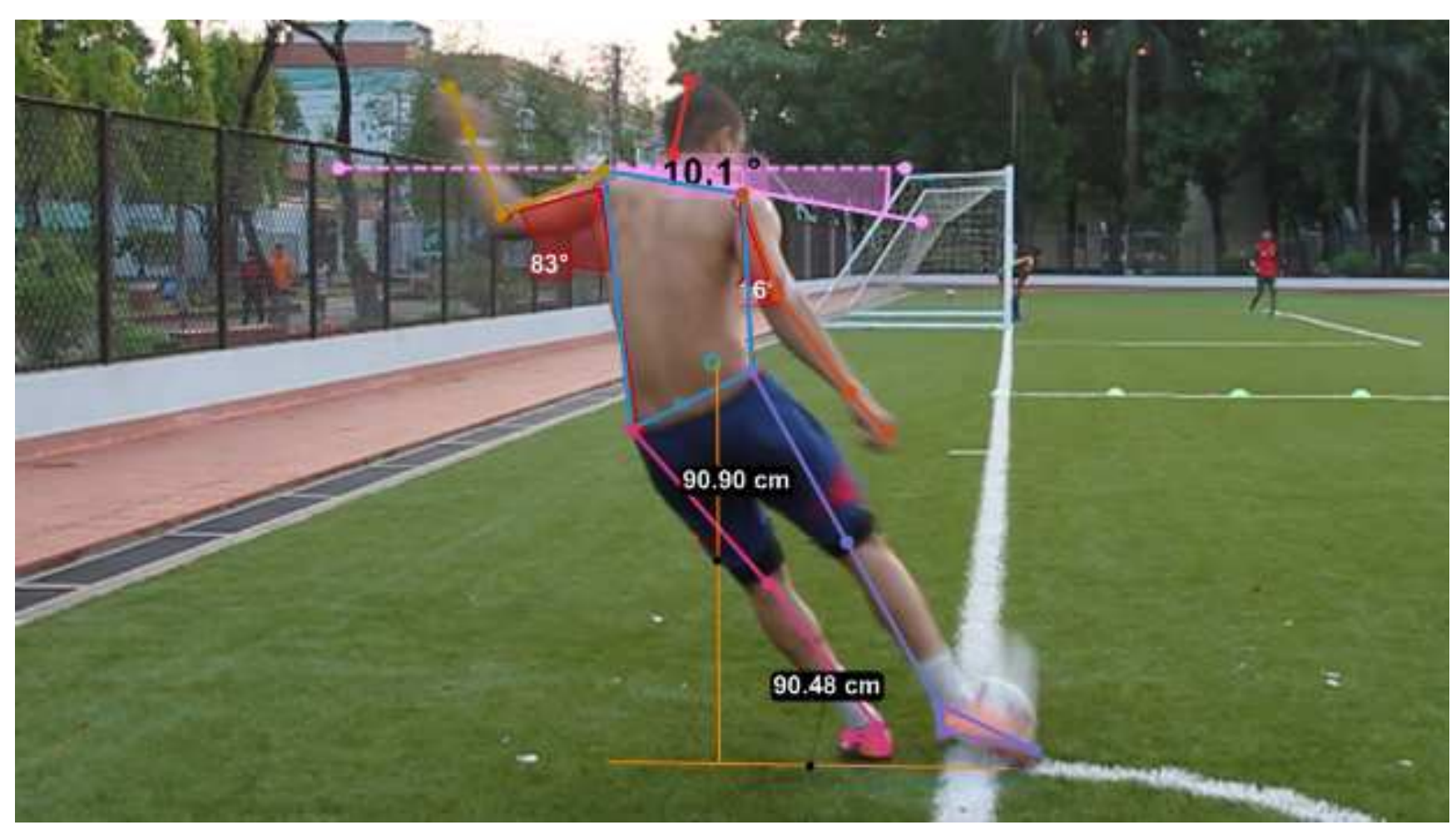

Figure 4. $C G P 2$.

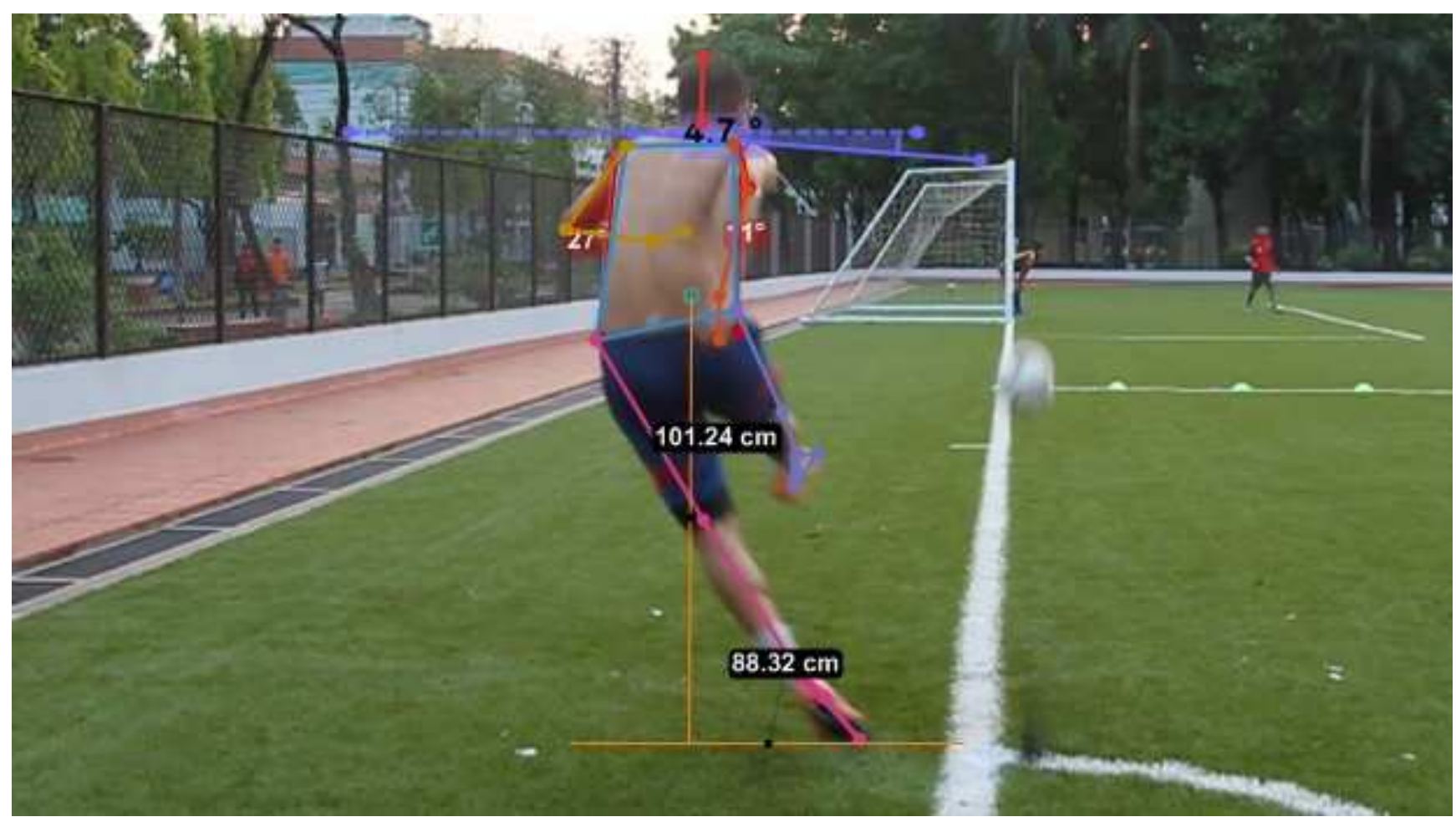

Figure 5. $C G P 3$.

\subsection{Analysis of Captured Action of Kicks}

By the help of 2D motion analysis software Kinovea 0.8 .25 , digitalized $\mathrm{CG}$ of the performed actions of selected soccer kicks to extract numerical data for the quantitative analysis.

\subsection{Statistical Procedure}

The scholars for the analysis of data used the SPSS 22.00 Statistical software packages. At the very outset, Data normality was tested using the Shapiro-Wilk test. Mean, Mann-Whitney U test and Kruskal-Wallis statistical tools 
were used for the analysis of data. Significance level was set at $\mathrm{p} \geq 0.05$.

\subsection{Terms Used}

\subsubsection{Ground Contact Phase (P1)}

First ground contact of the non-kicking foot in the last step just before the kick.

\subsubsection{Ball Contact Phase (P2)}

Ball contact with the kicking foot or execution phase.

\subsubsection{Follow-through Phase (P3)}

Maximum follow-through of kicking foot.

\section{Analysis of Data}

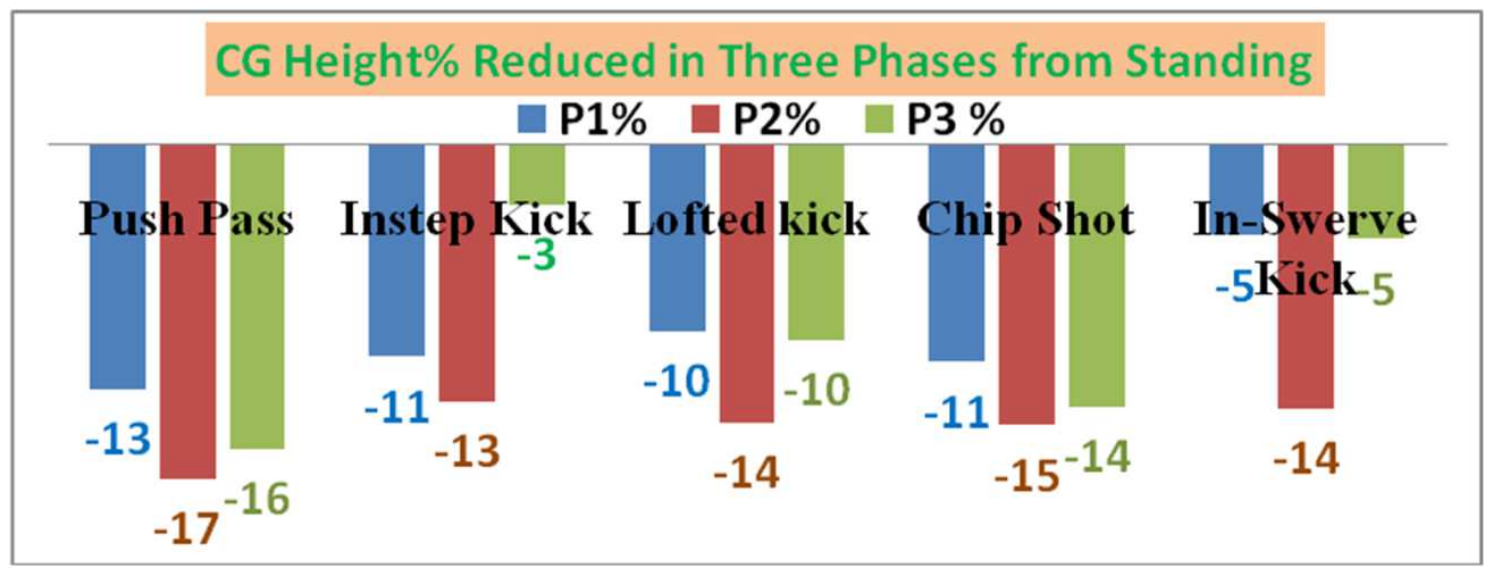

Figure 6. Mean CG height percentage changed in three different phases from erect standing CG height of selected kicks.

Table 1. Comparison of CG height percentage changed among soccer kicks in three different phases.

\begin{tabular}{|c|c|c|c|c|}
\hline \multicolumn{5}{|c|}{ Hypothesis Test Summary } \\
\hline$S L$ & Null Hypothesis & Test & Sig. & Decision \\
\hline 1 & $\begin{array}{l}\text { The distribution of } \mathrm{P} 1 \text { is the same across categories of } \\
\text { Soccer Kicks }\end{array}$ & $\begin{array}{l}\text { Independent-Sample Kruskal- } \\
\text { Wallis Test }\end{array}$ & 0.97 & $\begin{array}{l}\text { Retain the null } \\
\text { hypothesis }\end{array}$ \\
\hline 2 & $\begin{array}{l}\text { The distribution of } \mathrm{P} 2 \text { is the same across categories of } \\
\text { Soccer Kicks }\end{array}$ & $\begin{array}{l}\text { Independent-Sample Kruskal- } \\
\text { Wallis Test }\end{array}$ & 0.97 & $\begin{array}{l}\text { Retain the null } \\
\text { hypothesis }\end{array}$ \\
\hline 3 & $\begin{array}{l}\text { The distribution of P3 is the same across categories of } \\
\text { Soccer Kicks }\end{array}$ & $\begin{array}{l}\text { Independent-Sample Kruskal- } \\
\text { Wallis Test }\end{array}$ & 0.34 & $\begin{array}{l}\text { Retain the null } \\
\text { hypothesis }\end{array}$ \\
\hline
\end{tabular}

Asymptotic significances are displayed. The significance level is 0.05 .

Table 2. Comparison of CG height percentage changed within soccer kicks in three different phases.

\begin{tabular}{|c|c|c|c|c|}
\hline \multicolumn{5}{|c|}{ Hypothesis Test Summary } \\
\hline$S L$ & Null Hypothesis & Test & Sig. & Decision \\
\hline 1 & $\begin{array}{l}\text { The distribution of Push Pass is the same across categories of } \\
\text { phases }\end{array}$ & $\begin{array}{l}\text { Independent-Sample Kruskal-Wallis } \\
\text { Test }\end{array}$ & 0.68 & Retain the null hypothesis \\
\hline 2 & $\begin{array}{l}\text { The distribution of Instep Kick is the same across categories of } \\
\text { phases }\end{array}$ & $\begin{array}{l}\text { Independent-Sample Kruskal-Wallis } \\
\text { Test }\end{array}$ & 0.02 & Reject the null hypothesis \\
\hline 3 & $\begin{array}{l}\text { The distribution of Lofted Kick is the same across categories of } \\
\text { phases }\end{array}$ & $\begin{array}{l}\text { Independent-Sample Kruskal-Wallis } \\
\text { Test }\end{array}$ & 0.45 & Retain the null hypothesis \\
\hline 4 & $\begin{array}{l}\text { The distribution of Chip Shot is the same across categories of } \\
\text { phases }\end{array}$ & $\begin{array}{l}\text { Independent-Sample Kruskal-Wallis } \\
\text { Test }\end{array}$ & 0.70 & Retain the null hypothesis \\
\hline 5 & $\begin{array}{l}\text { The distribution of In-swerve Kick is the same across } \\
\text { categories of phases }\end{array}$ & $\begin{array}{l}\text { Independent-Sample Kruskal-Wallis } \\
\text { Test }\end{array}$ & 0.40 & Retain the null hypothesis \\
\hline
\end{tabular}

Asymptotic significances are displayed. The significance level is 0.05 .

Table 3. Pair-wise comparison of CG height percentage changed among Phases in performing Instep Kick.

\begin{tabular}{llll}
\hline Sample1-Sample2 & Test Statistics & Sig. & Adj. Sig. \\
\hline P3-P1 & 5.00 & 0.08 & 0.23 \\
P3-P2 & 7.6 & 0.01 & 0.02 \\
P1-P2 & -2.60 & 0.36 & 1.00 \\
\hline
\end{tabular}

Each row tests the null hypothesis that the Sample 1 and Sample 2 distributions are the same.

Asymptotic significances (2-sided tests) are displayed. The significance level is 0.05 . 


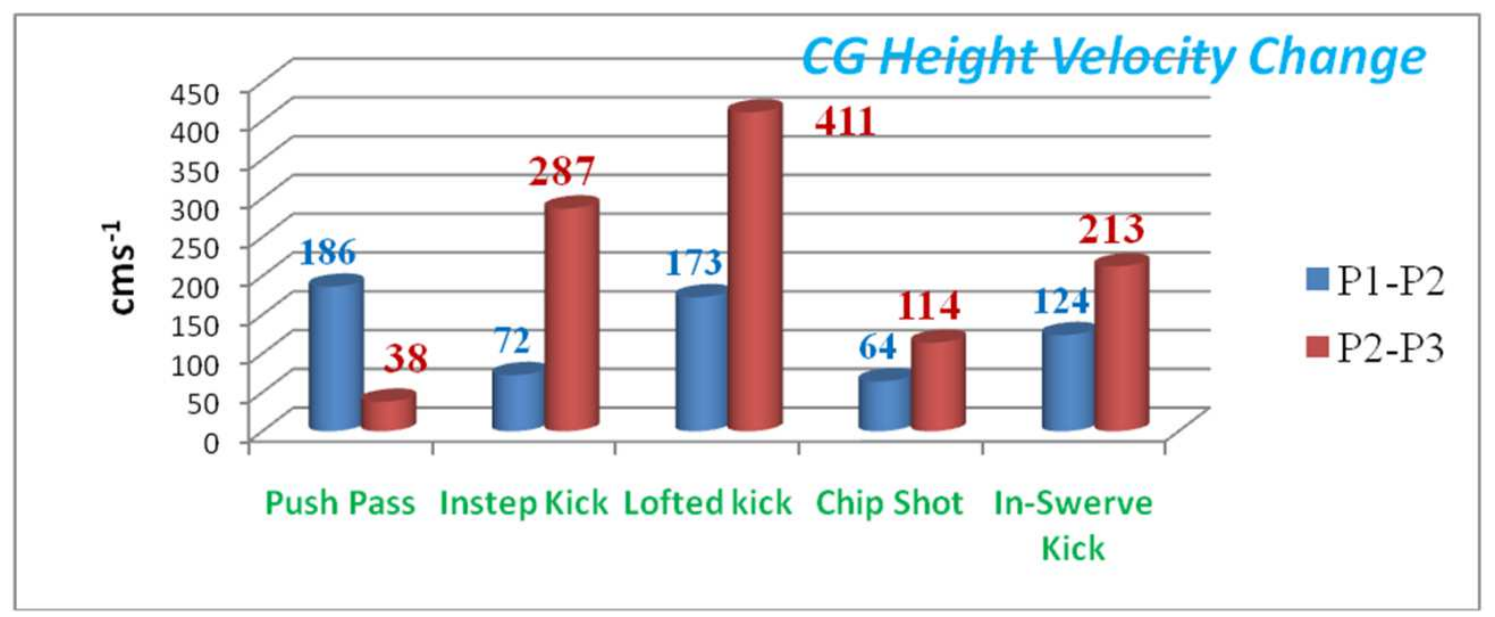

Figure 7. CG height mean velocity changed in selected soccer kicks in ball-contact and follow-through phases.

Table 4. Comparison of CG velocity between ball contact and follow-through phasesof selected soccer kicks.

\begin{tabular}{|c|c|c|c|c|}
\hline \multicolumn{5}{|c|}{ Hypothesis Test Summary } \\
\hline$S L$ & Null Hypothesis & Test & Sig. & Decision \\
\hline 1 & $\begin{array}{l}\text { The distribution of Push Pass is the same across categories } \\
\text { of phases }\end{array}$ & $\begin{array}{l}\text { Independent-Sample Mann-Whitney } \\
\text { U Test }\end{array}$ & 0.06 & Retain the null hypothesis \\
\hline 2 & $\begin{array}{l}\text { The distribution of Instep Kick is the same across } \\
\text { categories of phases }\end{array}$ & $\begin{array}{l}\text { Independent-Sample Mann-Whitney } \\
\text { U Test }\end{array}$ & 0.10 & Retain the null hypothesis \\
\hline 3 & $\begin{array}{l}\text { The distribution of Lofted Kick is the same across } \\
\text { categories of phases }\end{array}$ & $\begin{array}{l}\text { Independent-Sample Mann-Whitney } \\
\text { U Test }\end{array}$ & 0.42 & Retain the null hypothesis \\
\hline 4 & $\begin{array}{l}\text { The distribution of Chip Shot is the same across categories } \\
\text { of phases }\end{array}$ & $\begin{array}{l}\text { Independent-Sample Mann-Whitney } \\
\text { U Test }\end{array}$ & 0.55 & Retain the null hypothesis \\
\hline 5 & $\begin{array}{l}\text { The distribution of In-swerve is the same across categories } \\
\text { of phases }\end{array}$ & $\begin{array}{l}\text { Independent-Sample Mann-Whitney } \\
\text { U Test }\end{array}$ & 0.10 & Retain the null hypothesis \\
\hline
\end{tabular}

Asymptotic significances are displayed. The significance level is 0.05 .

Exact significance is displaced for this test.

Table 5. Comparison of CG velocity among selected soccer kicks in ball contact and follow-through phases.

\begin{tabular}{|c|c|c|c|c|}
\hline \multicolumn{5}{|c|}{ Hypothesis Test Summary } \\
\hline SL & Null Hypothesis & Test & Sig. & Decision \\
\hline 1 & $\begin{array}{l}\text { The distribution of P1-P2 is the same across categories of Soccer } \\
\text { Kicks }\end{array}$ & $\begin{array}{l}\text { Independent-Samples Kruskal- } \\
\text { Wallis Test }\end{array}$ & 0.16 & $\begin{array}{l}\text { Retain the null } \\
\text { hypothesis }\end{array}$ \\
\hline 2 & $\begin{array}{l}\text { The distribution of P2-P3 is the same across categories of Soccer } \\
\text { Kicks }\end{array}$ & $\begin{array}{l}\text { Independent-Samples Kruskal- } \\
\text { Wallis Test }\end{array}$ & 0.04 & $\begin{array}{l}\text { Reject the null } \\
\text { hypothesis }\end{array}$ \\
\hline
\end{tabular}

Asymptotic significances are displayed. The significance level is 0.05 .

Table 6. Pair-wise comparison of the CG velocity of soccer kicks of ball contact to follow-through phase.

\begin{tabular}{llll}
\hline Sample 1 - Sample 2 & Test Statistic & Sig. & Adj. Sig. \\
\hline Push Pass - Chip Shot & -4.90 & 0.29 & 1.00 \\
Push Pass - Instep Kick & -10.10 & 0.03 & 0.30 \\
Push Pass - In-swerve Kick & -10.10 & 0.03 & 0.30 \\
Push Pass - Lofted Kick & -12.90 & 0.00 & 0.06 \\
Chop Shot - Instep Kick & 5.20 & 0.26 & 1.00 \\
Chip Shot - In-swerve Kick & -5.20 & 0.26 & 1.00 \\
Chip Shot - Lofted Kick & 8.00 & 0.09 & 0.85 \\
Instep Kick - In-swerve Kick & 0.00 & 1.00 & 1.00 \\
Instep Kick - Lofted Kick & -2.80 & 0.55 & 1.00 \\
In-swerve Kick - Lofted Kick & 2.80 & 0.55 & 1.00 \\
\hline
\end{tabular}

Each row tests the null hypothesis that the Sample 1 and Sample 2 distributions are the same.

Asymptotic significances (2-sided tests) are displayed. The significance level is 0.05 .

\section{Result}

Figure 6 depicts the CG height percentage reduction in three different phases from erect standing position and illustrates that in all the kicks of CG height percentage reduction was maximum in the phase-2 (Minimum 13\% and Maximum 17\%) but in comparison to the phase-1 (Minimum 
5\% and Maximum 13\%) and phase-3 (Minimum 3\% and Maximum 16\%). Table 1 of Independent sample KruskalWallis test showing that when all the selected kicks were compared among themselves in P1, P2 and P3 significance values ware as found $p=0.97,0.97 \& 0.34$ respectively are higher than the accepted $\mathrm{p} \leq 0.05$. Table 2 of Independent sample Kruskal-Wallis test reveals that when a selected kick is compared within the phases in the Push Pass $p=0.68$, Lofted Kick $p=0.45$, chip Shot $p=0.70$, and In-swerve Kick $\mathrm{p}=0.40$ were found not statistically significant. On the contrary, Instep Kick the significant value $p=0.20$ was significant as the tabulated level was set $p \leq 0.05$. Table 3 proves that in the Instep Kick, statistically significant difference existed between P2 \& P3 as p $=0.01$, whereas no statistically significant difference existed between P1 \& P3 as $\mathrm{p}=0.08$ and $\mathrm{P} 1 \& \mathrm{P} 2$ as $\mathrm{p}=0.36$ as tabulated value $\mathrm{p} \leq 0.05$.

Figure 7 confirms that $\mathrm{CG}$ mean velocity change in selected kicks in ball contact and velocity within the Kick. Male players performed CG velocity in ball contact (P1-P2) and follow-through (P2-P3) phases in all selected kicks were without any synchronization. Where the velocity of followthrough phase was higher than ball contact phase except Push Pass. Table 4, independent sample Mann-Whitney U test of CG velocity comparison between ball contact and followthrough phases of selected soccer kicks interprets that male Soccer players carried out no statistically significant difference in CG velocities within the selected kicks when compared between the phases. Soccer male players executed CG velocity in selected kicks with the significance value as Push Pass $p=0.06$, Instep Kick $p=0.10$, Lofted Kick $p=$ 0.42 , Chip Shot $p=0.55$, and In-swerve $p=0.10$ as the tabulated level of significance was set $p \leq 0.05$. Table 5 shows the comparison of CG velocity among selected soccer kicks in phases of ball contact (P1-P2) and follow-through (P2-P3) and ball contact phase showed statistically not significant $\mathrm{p}=0.16$ and follow-through phase showed statistically significant $p=0.04$ as the level of significance was set $\mathrm{p} \leq 0.05$. Table 6 reveals that in the pair-wise comparison of the velocity of CGat ball contact to followthrough phase, statistically significant difference was identified between Push Pas \& Instep Kick p $=0.30$, Push Pass \& In-swerve Kick $p=0.03$, and Push Pass \& Lofted Kick $\mathrm{p}=0.00$. On the contrary, there were statistically no significant differences in CG velocity between Push Pass \& Chip Shot $p=0.29$, Chop Shot \& Instep Kick $p=0.26$, Chip Shot \& In-swerve $\mathrm{p}=0.26$, Chip Shot \& Lofted Kick $\mathrm{p}=$ 0.09 , Instep Kick \& In-swerve Kick p $=1.00$, Instep Kick \& Lofted Kick $\mathrm{p}=0.55$, and In-swerve Kick \& Lofted Kick $\mathrm{p}=$ 0.55 as tabulated value $\mathrm{p} \leq 0.05$.

\section{Discussion}

Male Soccer players experienced CG height reduction in three different phases in Push Pass, Instep Kick, Lofted Kick, Chip Shot, and In-swerve Kick in an inconsistent manner since execution techniques are different for different kicks in soccer. Table 1 shows there was no statistically significant difference in the performances among the selected soccer kicks when compared in three different phases. However, in terms of mean difference, a difference existed among the selected soccer kicks in each of the phases. Nevertheless, within the phase, there was no statistically significant difference maybe because of the small sample size, uniform participation level, and hence identical performance of the same players may be the result of no statistical differences in the reduction of $\mathrm{CG}$ heights of different phases of the kick. Comparison of $\mathrm{CG}$ height percentage changed within selected soccer kicks in three different phases presented in Tables $2 \& 3$ confirms that only difference existed in Instep Kick between ball contact and follow-through was due to the nature of the kick. It is the most powerful kick thus required the higher angular velocity of the kicking leg and that generated higher momentum of the kicking leg, which disturbed the equilibrium of the body. By lowering CG height, the body might have maintained dynamic equilibrium [4]. Furthermore, follow-through is a deceleration phase and in this phase, body needs to retain its original position to be ready for the next required action. In addition, in this kick, kicked ball velocity is higher among all other kicks in soccer $[17,18]$. The generated momentum is transferred to the ball in the usual mechanical phenomenon and in return ball also exerted equal and opposite reaction force to the leg that resulted in the reeducation of kicking leg's velocity in the follow-through phase [19].

Lower CG velocity at ground contact to ball contact phase in comparison to ball contact to maximum follow-through phase indicates that male soccer players might have done it to maintain dynamic stability as kicking leg's momentum is high in Instep Kick, which results in the fastest kick in Soccer. SAITO, Miyawaki \& Kizawa concluded that lower extremity joint power at the time of squatting and walking has a quantitative association between the CG velocity [20, 21]. No significant differences in the table 4 in $C G$ velocity between ground contact to ball contact and ball contact to maximum follow-through phases in all the selected soccer kicks have been observed. In ball contact (P1-P2) phase the CG velocity was not significantly different, however their differential mean values may be subjected to the cause of maintenance of dynamic stability. Slower CG velocity in follow-through (P3) phase of Push Pass in comparison to Instep Kick, Lofted Kick, and In-swerve Kick resulted from highest momentum in later kicks compare to the former one.

\section{Conclusion}

Male soccer players demonstrate inconsistency in $\mathrm{CG}$ height reduction in performing all the phases (Ground Contact, Ball Contact, and Follow-through) in all selected five kicks (Push Pass, Instep Kick, Lofted Kick, Chip Shot, and In-swerve Kick), but highest reductions have been located in the ball contact phase of all the kicks. Players change CG height in the same manner among the five selected kicks in each of the phases distinctly. Players experience $\mathrm{CG}$ height drop in Instep Kick differently 
between ball contact and ground contact phases. Players display higher mean $C G$ velocity in ball contact phase than follow-through phase in Push Pass, remaining other kicks exhibit opposite actions. Players display CG velocity in all selected soccer kicks in the same manner at ball contact and follow-through phases. Players change CG velocity differently between Push Pass and Instep Kick, In-swerve Kick, Lofted Kick at follow-through phase.

\section{References}

[1] P. M. McGinnis, BIOMECHANICS OF SPORT AND EXERCISE, Human Kinetics, Champaingn, United States of America, 1999. http://www.humankinetics.com/.

[2] Dictionary.com, Definition of centre of gravity Dictionary.com, Www.dictionary.com. (n. d.). https://www.dictionary.com/browse/centre-of-gravity (accessed August 30, 2019).

[3] R. Rai, Biomechanics Mechanical Aspects of Human Motion, Agrim Publication, Mohali, Punjab, 2003.

[4] C. Hobbs, Importance of Balance and Stability to Mastery of Sport Skills | The Sport Digest, (2010). http://thesportdigest.com/archive/article/importance-balanceand-stability-mastery-sport-skills (accessed August 30, 2019).

[5] S. Boukhenous, M. Attari, Y. Remram, An Easy Platform for Postural Balance Analysis by the Evaluation of Instantaneous Center of Gravity | Elsevier Enhanced Reader, APCBEE Procedia. 7 (2013). doi: 10.1016/j.apcbee.2013.08.004.

[6] C. Woodford, Center of gravity - A basic explanation of balancing weight, Explain Stuff. (2018). http://www.explainthatstuff.com/center-of-gravity.html (accessed August 31, 2019).

[7] S. A. Khadir, R. Lowe, L. Ritchie, S. Buxton, T. Lowe, Centre of Gravity, Physiopedia. (2018). https://www.physiopedia.com/Centre_of_Gravity (accessed March 19, 2018).

[8] T. Nakamura, T. Miyoshi, M. Takagi, Y. Kamada, Synchronized lower limb kinematics with pelvis orientation achieves the non-rotational shot, Sports Eng. Springer Sci. Bus. Media BV. 19 (2016) 71.

[9] K. Sakamoto, G. Geisler, M. Nakayama, T. Asai, Kinematic analysis of the ball impact in female soccer players, Procedia Eng. 13 (2011) 182-187. doi: 10.1016/j.proeng.2011.05.070.

[10] E. Çetin, S. Muratl1, Analysis of Jump Shot Performance among 14-15 Year Old Male Basketball Player, Procedia Soc. Behav. Sci. 116 (2014) 2985-2988. doi: 10.1016/j.sbspro.2014.01.693.
[11] D. V. M. Spathopoulos, AN INTRODUCTION TO THE $\begin{array}{lll}\text { PHYSICS OF } & \text { SPORTS, }\end{array}$ https://www.topendsports.com/biomechanics/center-ofgravity.htm (accessed August 31, 2019).

[12] M. Maeda, Effects of baseball bat mass and position of center of gravity on batting, Procedia Eng. 2 (2010) 2675-2680. doi: 10.1016/j.proeng.2010.04.050.

[13] G. Martens, D. Deflandre, C. Schwartz, N. Dardenne, T. Bury, Reproducibility of the Evolution of Stride Biomechanics During Exhaustive Runs, J. Hum. Kinet. 64 (2018) 57.

[14] T. Tanaka, H. Takeda, T. Izumi, S. Ino, T. Ifukube, Effects on the location of the centre of gravity and the foot pressure contribution to standing balance associated with ageing, Ergonomics. (1999) 997.

[15] D. Ö. Kaplan, Evaluating the Effect of 12 Weeks Football Training on the Posture of Young Male Basketball Players, J. Educ. Train. Stud. 6 (2018) 47-53.

[16] G. Pahnabi, M. Ahmadi, M. Akbari, N. N. Ansari, M. Mardani, M. Rostami, Comparison of the postural control between football players following ACL reconstruction and healthy subjects, Med. J. Islam. Repub. Iran. 28 (2014) 1.

[17] K. Sakamoto, N. Numazu, S. Hong, T. Asai, Kinetic Analysis of Instep and Side-foot Kick in Female and Male Soccer Players, Procedia Eng. 147 (2016) 214-219. doi: 10.1016/j.proeng.2016.06.216.

[18] H. Nunome, T. Asai, Y. Ikegami, S. Sakurai, Threedimensional kinetic analysis of side-foot and instep soccer kicks, Med. Sci. Sports Exerc. 34 (2002) 2028.

[19] P. Teerikorpi, M. Valtonen, K. Lehto, H. Lehto, G. Byrd, A. Chernin, eds., Newton, in: Evol. Universe Orig. Life Search Our Cosm. Roots, Springer New York, New York, NY, 2009: pp. 103-109. doi: 10.1007/978-0-387-09534-9_10.

[20] A. SAITO, K. Miyawaki, S. Kizawa, A study on estimating the center of gravity velocity using lower limb joint power during squatting, Trans. JSME Jpn. (2017). doi: 10.1299/transjsme.17-00234.

[21] A. SAITO, Y. NARA, K. Miyawaki, Center of gravity velocity estimation using lower limb joint power during walking, Research Gate. (2019). https://www.researchgate.net/publication/335353940_Center_ of_gravity_velocity_estimation_using_lower_limb_joint_pow er_during_walkingbuxingdongzuoniokeruxiazhiguanjiepawaw oyongitashentizhongxinsudunotuidingniguansuruyanjiu (accessed September 27, 2019). 